\title{
BMJ Open Marital status and survival after oesophageal cancer surgery: a population-based nationwide cohort study in Sweden
}

\author{
Nele Brusselaers, ${ }^{1}$ Fredrik Mattsson, ${ }^{1}$ Asif Johar, ${ }^{2}$ Anna Wikman, ${ }^{2}$ \\ Pernilla Lagergren, ${ }^{2}$ Jesper Lagergren, ${ }^{1,3}$ Rickard Ljung ${ }^{1,4}$
}

To cite: Brusselaers N, Mattsson F, Johar A, et al. Marital status and survival after oesophageal cancer surgery: a population-based nationwide cohort study in Sweden. BMJ Open 2014;4: e005418. doi:10.1136/ bmjopen-2014-005418

- Prepublication history for this paper is available online. To view these files please visit the journal online (http://dx.doi.org/10.1136/ bmjopen-2014-005418).

Received 7 April 2014 Revised 13 May 2014 Accepted 16 May 2014

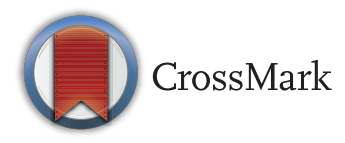

${ }^{1}$ Unit of Upper Gastrointestinal Surgery, Department of Molecular Medicine and Surgery, Karolinska Institutet, Stockholm, Sweden ${ }^{2}$ Surgical Care Science, Department of Molecular Medicine and Surgery, Karolinska Institutet, Stockholm, Sweden ${ }^{3}$ Division of Cancer Studies, King's College London, London, UK

${ }^{4}$ Unit of Epidemiology, Institute of Environmental Medicine, Karolinska Institutet, Stockholm, Sweden

Correspondence to Dr Nele Brusselaers; nele.brusselaers@ki.se

\section{ABSTRACT}

Objectives: A beneficial effect of being married on survival has been shown for several cancer types, but is unclear for oesophageal cancer. The objective of this study was to clarify the potential influence of the marital status on the overall and disease-specific survival after curatively intended treatment of oesophageal cancer using a nationwide populationbased design, taking into account the known major prognostic variables.

Design: Prospective, population-based cohort.

Setting: All Swedish hospitals performing surgery for oesophageal cancer during 2001-2005.

Participants: This study included $90 \%$ of all patients with oesophageal or junctional cancer who underwent surgical resection in Sweden in 2001-2005, with followup until death or the end of the study period (2012).

Primary and secondary outcome measures: Cox regression was used to estimate associations between the marital status and the 5-year overall and diseasespecific mortality, expressed as HRs with $95 \% \mathrm{Cls}$, with adjustment for sex, age, tumour stage, histological type, complications, comorbidities and annual surgeon volume.

Results: Of all 606 included patients ( $80.4 \%$ men), $55.1 \%$ were married, $9.2 \%$ were remarried, $22.6 \%$ were previously married and $13 \%$ were never married. Compared with the married patients, the never married (HR 1.02, 95\% Cl 0.77 to 1.35), previously married (HR $0.90,95 \% \mathrm{Cl} 0.71$ to 1.15$)$ and remarried patients (HR $0.79,95 \% \mathrm{Cl} 0.55$ to 1.13 ) had no increased overall 5year mortality. The corresponding HRs for diseasespecific survival, and after excluding the initial 90 days of surgery, were similar to the HRs for the overall survival.

Conclusions: This study showed no evidence of a better 5-year survival in married patients compared with nonmarried patients undergoing surgery for oesophageal cancer.

\section{INTRODUCTION}

The potential influence of the marital status on health and life expectancy has long been a matter of discussion. ${ }^{12}$ Being married has

\section{Strengths and limitations of this study}

Patients with oesophageal cancer have a poor prognosis, even those patients eligible for curative surgery (oesophagectomy).

- Being married has been shown to be a marker of better survival after cancer in general and of specific types, but this has not been studied yet for oesophageal cancer.

- This nationwide population-based study did not find any evidence that the marital status influences long-term survival after oesophagectomy for oesophageal cancer, even after taking into account the known major prognostic variables.

- The absence of a clear association between marital status and long-term survival might be a false-negative result related to the relatively small sample size. Yet, it is also possible that the beneficial effect of being married is non-existent for oesophageal cancer.

- The main strength of this study is the population-based design with almost complete coverage, and complete follow-up of all patients operated in Sweden for oesophageal cancer in 2001-2005. Moreover, complete data on a large variety of variables enabled adjustment for known prognostic factors. Yet, among limitations are that the influence of other confounders or residual confounding by the variables adjusted for can never be ruled out. The statistical power was however limited to detect weak associations.

been shown to be a marker of better survival after cancer in general and of specific types, ${ }^{3}$ and the survival discrepancy between married and non-married patients with cancer has been claimed to be increasing over time. ${ }^{4}$ Having a partner is believed to lead to a healthier lifestyle, for example, regarding tobacco and alcohol use, physical activity and social support, and can also influence the choice and adherence to treatment, as well as the time elapsing between early 
symptoms and a confirmed cancer diagnosis. ${ }^{2}$ However, little is known about such an influence on oesophageal cancer. Only a few studies have investigated the potential role of socioeconomic factors in the prognosis of oesophageal cancer. ${ }^{5}{ }^{6}$ A previous study by our group showed limited evidence of an association between lower education and worse long-term survival in operated patients with oesophageal cancer (only a significant difference in patients with tumour stage IV) ${ }^{7} \mathrm{~A}$ recent American study showed that married patients were more likely to be diagnosed with localised disease, and received treatment with curative intent more frequently than non-married patients, also showing a better overall survival. ${ }^{8}$ However, patients with oesophageal cancer have an overall very poor prognosis, mainly due to advanced tumour at the time of diagnosis, and only a minority is eligible for curatively intended treatment. ${ }^{9}$ Surgery (oesophagectomy) plays a main role in the curatively intended therapy for most oesophageal cancer. ${ }^{9}$ The objective of this study was to clarify the potential influence of the marital status on the overall and disease-specific survival after curatively intended treatment of oesophageal cancer using a nationwide population-based design, taking into account the known major prognostic variables.

\section{METHODS}

\section{Participants}

This was a population-based prospective cohort study, which included $90 \%$ of all patients with oesophageal or gastro-oesophageal junctional cancer treated with surgery and the treatment of choice for potentially curable patients in Sweden during the study period, from 2 April 2001 to 31 December 2005. Follow-up for survival ended in 31 August 2012. The median duration of follow-up was 619 days. From the full cohort of 616 patients, 10 patients were excluded because of missing values for the marital status, leaving 606 patients for final analysis.

Informed consent was obtained from each patient before inclusion in the study.

\section{Data sources}

The organisation of the comprehensive nationwide network of clinicians that participated in the data collection has been described elsewhere, and most parts of the design of this clinical cohort study have been presented in detail. ${ }^{10}{ }^{11}$ In brief, information about the tumour stage, histology and localisation, surgical procedures and complications was prospectively collected for all patients through scrutiny of relevant medical records from 174 hospital departments in Sweden. ${ }^{11}$ In September 2012, the cohort was linked to the Patient Register, the Causes of Death Register and the Longitudinal Integration Database for Health Insurance and Labour Market Studies (LISA). The Patient Register includes all in-hospital care and outpatient specialist care in Sweden, including codes for diagnoses, surgical procedures and comorbidity with a high level of validity. ${ }^{12}$ The Causes of Death Register contains information on the date and cause of death for all deceased Swedish residents since $1952 .{ }^{13}$ The LISA came into use in 1990 and includes a large variety of variables, including socioeconomic status, marital status and work history. ${ }^{14}$

\section{Study exposure and outcome}

Four mutually exclusive categories for marital status during the calendar year before surgery were married (never divorced or widowed), remarried (after widowhood or divorce), previously married (widowed or divorced) and never married. An additional analysis was performed grouping all patients into two groups: the currently married (married and remarried) and the not currently married patients (previously married and never married).

The main outcome measure was the overall mortality (including all causes of death) up to 5 years after oesophagectomy for oesophageal cancer. Other outcomes were mortality within 5 years after surgery: (1) after exclusion of deaths within first 90 days of surgery (defined as conditional mortality), (2) with oesophageal cancer as an underlying or contributing cause of death (disease-specific mortality or death related to oesophageal cancer) and (3) the combination of conditional and disease-specific mortality.

\section{Statistical analyses}

The association between marital status and mortality was analysed by means of multivariable Cox regression and expressed as HRs with 95\% CIs. The married group was used as the reference category. Three regression models were employed: (1) without any adjustments (crude model), (2) adjusted for sex, age and tumour stage (basic model) and (3) further adjusted for histological tumour type, major complications, comorbidities and annual surgeon volume for oesophagectomy for cancer (fully adjusted model). ${ }^{15}$ Owing to the limited effect on survival, as shown in a previous study, ${ }^{7}$ the educational level was not included in the analyses. The age was categorised as $<60,60-74$ or $\geq 75$ years, and the tumour stage as $0-\mathrm{I}$, II, III or IV according to the sixth edition of the UICG (Union Internationale Contre le Cancer). ${ }^{16}$ The histological type was subdivided into adenocarcinoma and squamous cell carcinoma. Numbers of major complications (within 30 days of surgery) and comorbidities were categorised as none, one or more than one, as described previously. ${ }^{11} 17$ The surgeon volume was categorised into two equally sized groups based on the median annual number of oesophagectomies per surgeon $(<8$ or $\geq 8) \cdot{ }^{15}$ To assess effect modification, stratified survival analyses were performed for the tumour stage and histological type using the same regression models, without adjustment for the stratifying variable. 


\section{RESULTS}

\section{Patients}

Characteristics of the 606 study patients are described in table 1 . At the time of surgery, 334 patients were married $(55.1 \%), 56$ were remarried $(9.2 \%), 137$ were married previously $(22.6 \%)$ and 79 patients were never married (13\%). Compared with the married group, the remarried and never married groups were younger (table 1 ). The largest proportion of male patients was found in the never married group $(87.3 \%)$ and the smallest in the previously married group $(75.2 \%)$. Tumours were as likely to be of an advanced stage (stage IV) in all four groups (range 10.2-12\%), but fewer early tumours (stage I) were found in the never married group $(12.7 \%)$ compared with the married group $(20.7 \%)$. Squamous cell carcinoma was found more frequently in the previously married (29.9\%) and never married groups (30.4\%), compared with the married $(21.3 \%)$ and remarried group $(23.2 \%)$. Of all patients, 53.6-62.8\% had comorbidity at the time of surgery, which was least in the remarried group. Married patients were least likely to have been operated on by surgeons with a low annual volume, compared with previously married patients ( $49.4 \%$ vs $58.4 \%)$. There were postoperative complications in $35.6-41.8 \%$ of the patients. In total, 455 (75.1\%) patients died within 5 years of surgery, of whom 429 $(94.3 \%)$ had oesophageal cancer as an underlying or contributing cause of death.

\section{Marital status and mortality}

The proportions of the overall and conditional 5-year mortality were highest in the never married group (table 1). The absolute 5-year survival rates for married, remarried, previously married and never married patients were $25.7 \%, 37.5 \%, 22.6 \%$ and $16.5 \%$, respectively. Short-term mortality was slightly lower in the never married group (6.3\% vs $8.1-8.9 \%$ in the other groups; table 1$)$. The HRs for mortality after oesophagectomy according to the marital status are presented in table 2. Compared with the married group, no increased HRs of mortality were found

Table 1 Demographic, treatment and tumour characteristics and mortality after oesophagectomy for cancer, categorised by the marital status at the time of diagnosis

\begin{tabular}{|c|c|c|c|c|c|}
\hline & \multicolumn{4}{|c|}{ Marital status } & \multirow[b]{2}{*}{$\begin{array}{l}\text { Total } \\
\mathrm{N}(\%) \\
\end{array}$} \\
\hline & $\begin{array}{l}\text { Married } \\
\text { N (\%) }\end{array}$ & $\begin{array}{l}\text { Remarried } \\
\mathrm{N}(\%)\end{array}$ & $\begin{array}{l}\text { Previously married }^{*} \\
\mathrm{~N}(\%)\end{array}$ & $\begin{array}{l}\text { Never married } \\
\mathrm{N}(\%)\end{array}$ & \\
\hline Total & $334(55.1)$ & $56(9.2)$ & $137(22.6)$ & $79(13.0)$ & $606(100.0)$ \\
\hline \multicolumn{6}{|l|}{ Age (years) } \\
\hline$<60$ & $63(18.9)$ & $18(32.1)$ & 31 (22.6) & $33(41.8)$ & $145(23.9)$ \\
\hline $60-74$ & 199 (59.6) & $34(60.7)$ & $69(50.4)$ & $37(46.8)$ & 339 (55.9) \\
\hline$\geq 75$ & $72(21.6)$ & $4(7.1)$ & $37(27.0)$ & $9(11.4)$ & $122(20.1)$ \\
\hline \multicolumn{6}{|l|}{ Sex } \\
\hline Male & $270(80.8)$ & $45(80.4)$ & $103(75.2)$ & 69 (87.3) & $487(80.4)$ \\
\hline Female & 64 (19.2) & $11(19.6)$ & $34(24.8)$ & $10(12.7)$ & 119 (19.6) \\
\hline \multicolumn{6}{|l|}{ Tumour stage } \\
\hline -1 & $69(20.7)$ & $12(21.4)$ & $23(16.8)$ & $10(12.7)$ & $114(18.8)$ \\
\hline II & $100(29.9)$ & $12(21.4)$ & $42(30.7)$ & $24(30.4)$ & $178(29.4)$ \\
\hline III & $125(37.4)$ & $26(46.4)$ & $58(42.3)$ & $36(45.6)$ & $245(40.4)$ \\
\hline IV & $40(12.0)$ & $6(10.7)$ & $14(10.2)$ & $9(11.4)$ & $69(11.4)$ \\
\hline \multicolumn{6}{|l|}{ Histology } \\
\hline Adenocarcinoma & $263(78.7)$ & $43(76.8)$ & $96(70.1)$ & 55 (69.6) & $457(75.4)$ \\
\hline Squamous cell carcinoma & 71 (21.3) & $13(23.2)$ & $41(29.9)$ & $24(30.4)$ & $149(24.6)$ \\
\hline \multicolumn{6}{|l|}{ Comorbidity } \\
\hline None & $126(37.7)$ & $26(46.4)$ & $51(37.2)$ & $33(41.8)$ & 236 (38.9) \\
\hline One & $117(35.0)$ & $21(37.5)$ & $49(35.8)$ & $25(31.7)$ & $212(35.0)$ \\
\hline More than one & $91(27.3)$ & $9(16.1)$ & $37(27.0)$ & $21(26.6)$ & $158(26.1)$ \\
\hline \multicolumn{6}{|c|}{ Surgical volume (operations/year) } \\
\hline Low $(<8)$ & $165(49.4)$ & $30(53.6)$ & $80(58.4)$ & $43(54.4)$ & $318(52.5)$ \\
\hline High $(\geq 8)$ & $169(50.6)$ & $26(46.4)$ & $57(41.6)$ & $36(45.6)$ & $288(47.5)$ \\
\hline \multicolumn{6}{|l|}{ Postoperative complications } \\
\hline None & $215(64.4)$ & $35(62.5)$ & $85(62.0)$ & $46(58.2)$ & $381(62.9)$ \\
\hline One & $85(25.5)$ & $14(25.0)$ & $28(20.4)$ & $17(21.5)$ & $144(23.8)$ \\
\hline More than one & $34(10.2)$ & 7 (12.5) & $24(17.5)$ & $16(20.3)$ & $81(13.4)$ \\
\hline \multicolumn{6}{|l|}{ Mortality, 90 days } \\
\hline Within 90 days & $27(8.1)$ & $5(8.9)$ & $11(8.0)$ & $5(6.3)$ & $48(7.9)$ \\
\hline Overall within 5 years & $248(74.3)$ & $35(62.5)$ & $106(77.4)$ & 66 (83.5) & $455(75.1)$ \\
\hline Conditional within 5 years $†$ & $221(72.0)$ & $30(58.8)$ & 95 (75.4) & $61(82.4)$ & 407 (72.9) \\
\hline
\end{tabular}

*Previously married was defined as patients who have been married before but are living alone (after the death of the partner or divorce). †Conditional mortality: excluding first 90 days after surgery. 
Table 2 Multivariable Cox regression models analysing the association between the marital status at the time of diagnosis and mortality after oesophagectomy for cancer, expressed as HRs with $95 \% \mathrm{Cls}$

\begin{tabular}{|c|c|c|c|c|}
\hline & \multicolumn{4}{|l|}{ Marital status } \\
\hline & Married (reference) & $\begin{array}{l}\text { Remarried HR } \\
(95 \% \mathrm{Cl})\end{array}$ & $\begin{array}{l}\text { Previously married }{ }^{\star} \\
\text { HR }(95 \% \mathrm{Cl})\end{array}$ & $\begin{array}{l}\text { Never married } \\
\mathrm{HR}(95 \% \mathrm{Cl})\end{array}$ \\
\hline \multicolumn{5}{|c|}{ Overall 5-year mortality } \\
\hline Model 1 & 1 & $0.77(0.54$ to 1.10$)$ & 1.09 (0.87 to 1.37$)$ & $1.14(0.87$ to 1.49$)$ \\
\hline Model 2 & 1 & 0.79 (0.55 to 1.13$)$ & $0.95(0.75$ to 1.20$)$ & $1.03(0.78$ to 1.36$)$ \\
\hline Model 3 & 1 & $0.79(0.55$ to 1.13$)$ & $0.90(0.71$ to 1.15$)$ & $1.02(0.77$ to 1.35$)$ \\
\hline \multicolumn{5}{|c|}{ Conditional† overall 5-year mortality } \\
\hline Model 1 & 1 & $0.73(0.50$ to 1.07$)$ & $1.11(0.87$ to 1.41$)$ & $1.18(0.89$ to 1.57$)$ \\
\hline Model 2 & 1 & 0.73 (0.50 to 1.08$)$ & $0.96(0.75$ to 1.23$)$ & $1.04(0.78$ to 1.38$)$ \\
\hline Model 3 & 1 & $0.74(0.50$ to 1.08$)$ & $0.93(0.72$ to 1.20$)$ & $1.05(0.78$ to 1.41$)$ \\
\hline \multicolumn{5}{|c|}{ Disease-specific $\ddagger$ 5-year mortality } \\
\hline Model 1 & 1 & $0.79(0.56$ to 1.13$)$ & $1.11(0.88$ to 1.40$)$ & $1.19(0.89$ to 1.57$)$ \\
\hline Model 2 & 1 & $0.80(0.56$ to 1.15$)$ & $0.96(0.76$ to 1.22$)$ & $1.03(0.77$ to 1.34$)$ \\
\hline Model 3 & 1 & $0.80(0.56$ to 1.15$)$ & $0.92(0.72$ to 1.17$)$ & 1.04 (0.78 to 1.39$)$ \\
\hline \multicolumn{5}{|c|}{ Conditional† disease-specific $\ddagger$ 5-year mortality } \\
\hline Model 1 & 1 & $0.75(0.51$ to 1.10$)$ & $1.12(0.87$ to 1.43$)$ & $1.21(0.90$ to 1.63$)$ \\
\hline Model 2 & 1 & $0.74(0.50$ to 1.09$)$ & $0.97(0.76$ to 1.25$)$ & $1.02(0.76$ to 1.38$)$ \\
\hline Model 3 & 1 & $0.74(0.51$ to 1.10$)$ & $0.94(0.73$ to 1.22$)$ & $1.05(0.78$ to 1.42$)$ \\
\hline \multicolumn{5}{|c|}{$\begin{array}{l}\text { Values are expressed as HRs. } \\
\text { *Previously married was defined as patients who have been married before but are living alone (after the death of the partner or divorce). } \\
\text { tConditional mortality: excluding first } 90 \text { days after surgery. } \\
\text { tDisease-specific mortality: oesophageal or junctional cancer as the underlying or contributing cause. Model } 1 \text { : unadjusted. Model } 2: \text { adjusted } \\
\text { for sex, age, tumour stage. Model } 3: \text { adjusted for sex, age, tumour stage, histology, major complications, comorbidity and surgeon volume. }\end{array}$} \\
\hline
\end{tabular}

in the other marital status groups. The fully adjusted HR for the overall 5-year mortality was similar in never married patients compared with married patients (HR $1.02,95 \%$ CI 0.77 to 1.35 ), and the corresponding HRs were very similar for disease-specific survival and survival after excluding the initial 90 days after surgery (table 2). The fully adjusted HR for the various definitions of 5-year mortality was lower in the remarried group (HR ranging from 0.74 to 0.80 ) and in the previously married group (HR ranging from 0.90 to 0.94 ), but no statistically significant associations were identified (table 2). The results for disease-specific survival, and for overall or disease-specific survival after excluding the initial 90 days of surgery, were all similar to the HRs for the overall survival (table 2). The fully adjusted HR for the overall mortality in the not currently married group is 0.98 (95\% CI 0.80 to 1.19 ) compared with the currently married group.

The fully adjusted subgroup analyses for all-cause and disease-specific mortality by tumour stage and histological type showed similar results to the main analyses, and no statistically significant associations were identified (data not shown).

\section{DISCUSSION}

This study did not show any improved survival among married patients with oesophageal cancer undergoing oesophagectomy compared with other marital status groups after adjustment for several prognostic variables.

The main strength of this study is the population-based design with almost complete coverage, and complete follow-up of all patients operated in Sweden for oesophageal cancer in 2001-2005. Moreover, complete data on a large variety of variables enabled adjustment for known prognostic factors. Yet, among limitations are that the influence of other confounders or residual confounding by the variables adjusted for can never be ruled out. The statistical power was limited to detect weak associations, but large effects of the marital status on survival in this cohort of patients with cancer are unlikely. Changes in the marital status after surgery were considered of limited impact on the results, since these only occurred in $3.3 \%$ of all patients. Moreover, we did not have data on cohabiting without being married, or the extent of social networks, which could have led to an underestimation of potential associations. Despite the multicentre design, differences between hospitals and treatment are unlikely to have influenced any associations between marital status and survival. Socioeconomic variables such as ethnicity and income level may have an impact on survival as well, yet the underlying mechanisms are different. Socioeconomic inequality is a measure for lifetime differences, whereas the marital status reflects social support at the time of the disease.

The absence of a clear association between marital status and long-term survival, such as that found for some other cancer types and oesophageal cancer in the large American study mentioned earlier (including all diagnosed patients), ${ }^{38}$ might be a false-negative result related to the relatively small sample size. Yet, it is also possible that the beneficial effect of being married is non-existent for patients with oesophageal cancer receiving surgery, 
which has a limited chance of survival despite its curative intent. ${ }^{9}$ Although being married might not influence the survival, social support might be beneficial for other reasons, including the health-related quality of life in these patients. To conclude, this study showed no evidence of improved survival of married patients compared with non-married patients after having undergone surgery for oesophageal cancer.

Contributors All the authors have made substantial contributions to conception and design of the article. $\mathrm{JL}$ and PL were responsible for the acquisition of the data. NB, FM and AJ performed the statistical analyses and interpretation of the data. NB has drafted the manuscript, and all the authors revised it critically for important intellectual content. All the authors have given final approval of the version to be published.

Funding This work was supported by the Swedish Research Council (SIMSAM) and the Swedish Cancer Society (Contract number: 13 0537).

Competing interests None.

Patient consent Obtained.

Ethics approval The Regional Ethical Review Board in Stockholm, Sweden.

Provenance and peer review Not commissioned; externally peer reviewed.

Data sharing statement No additional data are available.

Open Access This is an Open Access article distributed in accordance with the terms of the Creative Commons Attribution (CC BY 4.0) license, which permits others to distribute, remix, adapt and build upon this work, for commercial use, provided the original work is properly cited. See: http:// creativecommons.org/licenses/by/4.0/

\section{REFERENCES}

1. Berkson J. Mortality and marital status. Reflections on the derivation of etiology from statistics. Am J Public Health Nations Health 1962;52:1318-29.
2. Rendall MS, Weden MM, Favreault MM, et al. The protective effect of marriage for survival: a review and update. Demography 2011;48:481-506.

3. Bailey J. Effects of marital status on cancer incidence and survival rates. Am Fam Physician 2009;80:1052; author reply 52.

4. Kravdal $\mathrm{H}$, Syse A. Changes over time in the effect of marital status on cancer survival. BMC Public Health 2011;11:804.

5. Thrift AP, Nagle CM, Fahey PP, et al. Predictors of survival among patients diagnosed with adenocarcinoma of the esophagus and gastroesophageal junction. Cancer Causes Control 2012;23:555-64.

6. Gossage JA, Forshaw MJ, Khan AA, et al. The effect of economic deprivation on oesophageal and gastric cancer in a UK cancer network. Int J Clin Pract 2009;63:859-64.

7. Brusselaers N, Ljung R, Mattsson F, et al. Education level and survival after oesophageal cancer surgery: a prospective population-based cohort study. BMJ 2013;3:e003754.

8. Aizer AA, Chen $\mathrm{MH}$, McCarthy EP, et al. Marital status and survival in patients with cancer. J Clin Oncol 2013;31:3869-76.

9. Lagergren J, Lagergren P. Recent developments in esophageal adenocarcinoma. CA Cancer J Clin 2013;63:232-48.

10. Lagergren J, Bergström R, Lindgren A, et al. Symptomatic gastroesophageal reflux as a risk factor for esophageal adenocarcinoma. N Engl J Med 1999;340:825-31.

11. Viklund $P$, Lindblad $M$, Lu M, et al. Risk factors for complications after esophageal cancer resection: a prospective population-based study in Sweden. Ann Surg 2006;243:204-11.

12. Lagergren $\mathrm{K}$, Derogar $\mathrm{M}$. Validation of oesophageal cancer surgery data in the Swedish Patient Registry. Acta Oncol 2012;51:65-8.

13. Johansson LA, Westerling R. Comparing Swedish hospital discharge records with death certificates: implications for mortality statistics. Int J Epidemiol 2000;29:495-502.

14. Statistics-Sweden. Longitudinell integrationsdatabas för Sjukförsäkrings- och Arbetsmarknadsstudier (LISA) 1990-2009. 2011.

15. Brusselaers N, Mattsson F, Lagergren J. Hospital and surgeon volume in relation to long-term survival after oesophagectomy: systematic review and meta-analysis. Gut 2013. Published Online First: 22 Nov 2013. doi:10.1136/gutjnl-2013-306074

16. Sobin L, Wittekind C. International Union Against Cancer (UICC): classification of malignant tumours. 6th edn, 2002

17. Backemar L, Djärv T, Wikman A, et al. The role of diabetes and other co-morbidities on survival after esophageal cancer surgery in a population-based study. Am J Surg 2013;206:539-43. 